\title{
The Dopamine Transporter: Immunochemical Characterization and Localization in Brain
}

\author{
Brian J. Ciliax, ${ }^{1}$ Craig Heilman, ${ }^{1}$ Lidia L. Demchyshyn, ${ }^{2}$ Zdenek B. Pristupa, ${ }^{2}$ Ernesto Ince, ${ }^{1}$ Steven $M$. \\ Hersch, ${ }^{1}$ Hyman B. Niznik, ${ }^{2}$ and Allan I. Levey, ${ }^{1,2}$ \\ ${ }^{1}$ Emory University School of Medicine, Department of Neurology, Atlanta, Georgia 30322, and ${ }^{2}$ Clarke Institute of \\ Psychiatry, Laboratory of Molecular Neurobiology, Toronto, Ontario M5T 1R8, Canada
}

Antibodies specific for the dopamine transporter (DAT) were developed and characterized by immunoblot analysis, immunoprecipitation, and immunocytochemistry, and used for immunolocalization of transporter protein in rat brain at the light microscopic level. Antibodies targeting the N-terminus, the second extracellular loop, and the C-terminus were generated from fusion proteins containing amino acid sequences from these respective regions. Immunoblot analysis demonstrated that $\mathrm{N}$-terminus and loop antibodles were specific for expressed cloned DAT, recognized transporter protein in rat and human striatal membranes, and were sensitive to preabsorption with excess homologous fusion protein. Immunoprecipitation studies demonstrated that anti-DAT antisera recognized solubilized, radiolabeled DAT protein in a concentration-dependent manner. DAT immunocytochemistry with these antibodies were also sensitive to preabsorption with fusion protein and to lesions of dopaminergic mesostriatal and mesocorticolimbic pathways. Regional distribution of DAT coincided with established dopaminergic innervation of several regions, including ventral mesencephalon, medial forebrain bundle, and dorsal and ventral striatum. However, certain mismatches between immunocytochemical distributions of DAT and tyrosine hydroxylase were apparent, indicating that dopaminergic systems are heterogeneous and may use independent mechanisms for the regulation of dopamine levels in brain. The generation of specific DAT antibodies will permit further characterization of the cellular and subcellular localization of DAT protein, and of dopaminergic circuits in neurological and psychiatric disorders.

[Key words: dopamine transporter, antibody, immunoprecipitation, immunoblot, immunocytochemistry, localization, brain]

Dopamine neurotransmission is initiated by the presynaptic release of dopanine and terminated largely by its reuptake through a specific, sodium-dependent dopamine transporter (DAT). The synaptic concentration of dopamine, and, therefore, the level of

\footnotetext{
May 17, 1994; revised Aug. 17, 1994; accepted Ang. 30, 1994.

We thank Julie Staley, Yan Qian, Randy Blakely, Tim Ely, Clinton Kilts, and Marc Caron for technical assistance and helpful discussions during these studies. This work was supported by the Stanley Foundation, PO1 NS31937, and the American Parkinson's Disease Association.

Correspondence should be addressed to Allan I. Levey, Department of Neurology, Emory University School of Medicine, Woodruff Memorial Research Building, Suite 6000, Atlanta, GA 30322.

Copyright (C) 1995 Society for Neuroscience 0270-6474/95/151714-10\$05.00/0
}

dopamine receptor stimulation, is regulated by DAT activity. Through this mechanism, DAT may be critically involved in certain pharmacological or pathological conditions. For example, several psychotherapeutic drugs (e.g., antidepressants) and drugs of abuse (e.g., cocaine and $d$-amphetamine) bind to DAT with high affinity (Giros and Caron, 1993). Moreover, DAT has been proposed as the molecular site of action for the reinforcing mechanisms of drugs of abuse. In addition, DAT plays a role in the toxicity of 6-hydroxydopamine (6-OHDA) (Zigmond et al., 1990) and MPTP (Kopin and Markey, 1988) by transporting the toxin or toxic metabolite into the vulnerable cell, leading to dopaminergic cell death and parkinsonism. DAT binding sites have also been shown to be altered in Parkinson's Disease (Niznik et al., 1991; Chinaglia et al., 1992), progressive supranuclear palsy (Chinaglia et al., 1992), and Tourette's syndrome (Singer et al., 1991). The importance of these pathological alterations are yet to be determined, but suggest that DAT could play a pivotal role in the development of addictive, neurotoxic, neurological and psychiatric disorders.

Localization of DAT in brain tissue has been performed by uptake, binding, and hybridization assays, yet many questions remain about the precise location and role of DAT in dopaminergic circuits. Uptake of radiolabeled substrates has been used to assess the regional distribution of DAT activity (Boja et al., 1994), but low specificity of the substrates has limited interpretation of the results. High affinity radioligands have been used to determine the regional distribution of DAI binding sites (Donnan et al., 1989; Graybiel and Moratalla, 1989; Richfield, 1991; Mennicken et al., 1992); however, the presence of unrelated binding sites for some of these ligands (Niznik et al., 1990; Tyndale et al., 1991) and similar binding affinities of other ligands for multiple monoamine transporters [possibly due to the highly conserved transmembrane regions forming the uptake sites (Giros and Caron, 1993)], makes localization more difficult. Moreover, autoradiographic methods have limited resolution, which has restricted localization to the regional level. Finally, in situ hybridization has demonstrated DAT mRNA expression in mesencephalic dopamine cell groups (Giros et al., 1991; Shimada et al., 1992; Cerruti et al., 1993), but this method cannot detect the actual, functional DAT molecule, nor determine its subcellular distribution. Highly specific antibodies directed against unique regions of DAT provide an alternate method for characterization of the transporter protein with greater specificity and spatial resolution by immunocytochemistry.

In order to investigate DAT protein directly in brain tissue, we have developed monospecific antibodies directed at two ep- 
itopes that are divergent from other family members. We used fusion proteins containing either the N-terminus or second extracellular loop of human DAT to generate and purify rabbit polyclonal antibodies. A third epitope in the C-terminus did not produce efficient antibodies. The antibodies were characterized for reactivity with cloned and native brain proteins by Western blotting and immunoprecipitation. Light microscopic immunocytochemical studies using affinity-purified antibodies demonstrated the regional and cellular localization of DAT in rat brain.

\section{Materials and Methods}

$D A T-p G E X-2 T$ plasmid construction. Fusion proteins incorporating the $\mathrm{N}$-terminus ( $\mathrm{Nt}$; amino acids $\mathrm{l}-66$ ), the second extracellular loop (e2; amino acids $180-218$ ), or the C-terminus (Ct; amino acids 578-619) of human DAT (hDAT) (Pristupa et al., 1994) were produced with the pGEX-2T expression system (Smith and Johnson, 1988). For PCR amplification of these three subregions, deoxyoligonucleotide primers were synthesized (Biotechnolngy Service Center, Toronto) to encompass nucleotides 1 to 217 in the amino terminal (5'-CGTGGATCCATGAGTAAGAGCAAATGC-3' and '5'-ACGATGAATTCTCTTCTTGCCCCAG GT- $3^{\prime}$ ), nucleotides 556 to 673 in the second extracellular loop (5'-CGTGGATCCTGCAACAACTCCTGGAAC-3' and 5'-ACGATGAATTCGTTCAAAGTACTCGGC-3'), and nucleotides 1750 to 1876 in the carboxy-terminus ( $5^{\prime}$-CGTGGATCCTACAAGTTCTGCAGCCTG and 5'-ACGATGAATTCCCTTGAGCCAGTGGCG) of the cloned hDAT (Pristupa et al., 1994). To ensure successful subcloning and fragment orientation, primers were designed with two restriction sites (BamHI and EcoR I), in each forward and reverse primer, respectively (marked in above sequences by italics). Full length cesium-purified hDAT DNA and each pair of specific primers were subjected to 20 cycles of PCR (Perkin-Elmer/Cetus) containing 2.5 units Taq polymerize and $100 \mu \mathrm{M}$ dNTPs in a total volume of $100 \mu \mathrm{l}$. Each PCR cycle consisted of denaturation at $94^{\circ} \mathrm{C}$ for $1 \mathrm{~min}$, annealing at $60^{\circ} \mathrm{C}$ for 1 $\mathrm{min}$, and extension at $72^{\circ} \mathrm{C}$ for $1 \mathrm{~min}$. Aliquots $(20 \mu \mathrm{l})$ of amplified DNA were electrophoresed on a $1.5 \%$ low-melt agarose gel and subcloned into the BamH I and EcoR I sites of pGEX-2T (Smith and Johnson, 1988). Recombinants were sequenced by the dideoxynucleotide chain-termination method using Sequenase version 2.0 (U.S. Biochemicals) and 7-deaza-dGTP.

$D A T-F$ usion protein expression. Proteins were generated containing a $27 \mathrm{kDa}$ fragment of helminthic glutathione-S-transferase (GSI) fused at the $\mathrm{C}$-terminus with either $\mathrm{Nt}$, $\mathrm{e} 2$, or $\mathrm{Ct}$. The fusion proteins were expressed in $E$. coli (BL21 strain) cells transfected with the respective pGEX plasmids after 3-4 hr induction by isopropylthiogalactoside. Preand postinduction culture samples were analyzed by SDS PAGE to reveal intense de novo protein bands. The induced bacteria were lysed by incubation with lysozyme and repeated freezing and thawing. The fusion proteins were affinity purified from the bacterial lysates against immobilized glutathione (conjugated to epoxy-activated agarose; Sigma, St. Louis, MO) and eluted with excess free reduced glutathione. Yields were typically $10-25 \mathrm{mg} / \mathrm{liter}$ of culture. Purified fusion protein preparations were verified by SDS PAGE analysis.

Antibody production. Each of two New Zealand White rabbits were immunized for polyclonal antibody production with purified Nt, e2, and $\mathrm{Ct}$ fusion proteins. Both animals received monthly injections of approximately $200 \mu \mathrm{g}$ of each soluble purified fusion protein emulsified in Freund's adjuvant. Bleeds were obtained at 3 and 4 weeks postboost, clotted overnight at $4^{\circ} \mathrm{C}$, clarified, and the sera aliquotted and frozen at $-80^{\circ} \mathrm{C}$. Antibodies were affinity purified on the respective fusion proteins conjugated to Affi-Gel (Bio-Rad) affinity resin, as previously described (Ciliax et al., 1994).

Cell transfections. Human dopamine transporter (hDAT) cDNA subcloned into $\mathrm{pRc} / \mathrm{CMV}$ was used to transfect SK-N-MC cells using a calcium phosphate transfection system from Bethesda Research Labs, as previously described (Pifl et al., 1993). SK-N-MC cells were transfected at a density of $3 \times 10^{6}$ cells/well with hDAT and control plasmids ( $15 \mu \mathrm{g} \mathrm{DNA} /$ well). Human norepinephrine transporter (hNET) and human serotonin transporter (hSERT) cDNAs subcloned into $p$ Bluescript were used to transfect HeLa cells. HeLa cells were transfected at a density of $1 \times 10^{6}$ cells/well with these plasmids $(1 \mu \mathrm{g}$ DNA/well) by a liposome suspension method ( $3 \mu \mathrm{g}$ lipofectin/well, GIBCO). The transcription of each cDNA, inserted downstream of T7 promoter, was initiated by the bacteria phage T7 RNA polymerase cod- ed in cytoplasm by the recombinant vaccinia $V_{T 7-3}$, added (10 pfu/cell) $30 \mathrm{~min}$ prior to transfection. Cells were washed $12 \mathrm{hr}$ after transfection, scraped into phosphate-buffered saline, and harvested by centrifugation. The cell pellets were resuspended in Tris EDTA containing protcasc inhibitors and homogenized. Homogenates were aliquotted and stored at $-20^{\circ} \mathrm{C}$.

Immunoblot analysis. Western blots were performed as previously described (Levey et al., 1993; Ciliax et al., 1995). Briefly, membranes from SK-N-MC or HeLa cells transfected with monoamine transporter cDNAs, or membranes from rat or human striatum were fractionated by SDS polyacrylamide gel electrophoresis and transblotted onto PVDF membrane (Millipore). Blots were blocked with $5 \%$ dry milk in $50 \mathrm{~mm}$ Tris-buffered saline $\mathrm{pH} 7.4$ followed by overnight incubation with primary antibody $(0.5 \mu \mathrm{g} / \mathrm{ml})$ at $4^{\circ} \mathrm{C}$. Membranes were rinsed and incubated for $1 \mathrm{hr}$ with peroxidase-conjugated goat anti-rabbil IgG (Bio$\mathrm{Rad}$ ) at room temperature. Immunoreactivity was detected by enhanced chemiluminescence on film (Amersham). For preadsorption experiments, blots were incubated with primary antibody that had been preadsorbed with $100 \mu \mathrm{g}$ of homologous fusion protein for $30 \mathrm{~min}$ at room temperature.

Immunoprecipitation. Three hundred microliter aliquots of Protein A-Sepharose CL-4B, equilibrated with $50 \mathrm{~mm}$ Tris, $300 \mathrm{~mm} \mathrm{NaCl}, 10$ mM EDTA, pH 7.5, were incubated with 2 to $60 \mu$ l of anti-hDAT antiserum for $2 \mathrm{hr}$ at $4^{\circ} \mathrm{C}$ in a final volume of $600 \mu \mathrm{l}$. After centrifugation (2000 rpm for $1 \mathrm{~min}$ ), supernatants were harvested and the pellets washed three times with $1 \mathrm{ml}$ of equilibration buffer. Pellets were then incubated for $12 \mathrm{hr}$ at $4^{\circ} \mathrm{C}$ with $300 \mu \mathrm{l}$ of digitonin (1\%) solubilized membranes prepared from human caudate corresponding to approximately $200 \mathrm{fmol}$ of ${ }^{3} \mathrm{H}$-WIN35,428 or approximately $500 \mathrm{fmol}$ of ${ }^{3} \mathrm{H}-$ GBR-12935 binding activity, as described (Niznik et al., 1990). Following incubation $200 \mu \mathrm{l}$ aliquots of supernatant were incubated with ${ }^{3} \mathrm{H}$-WIN35,428 (40 nM final concentration) or ${ }^{3}$ H-GBR-12935 (10 nM) and assayed for residual DAT binding activity by Sephadex G-50 column chromatography as described. Nonspecific binding was determined in the presence of $500 \mathrm{nM}$ mazindol (Niznik et al., 1991). Control samples were incubated with protein A-Sepharose coupled with $60 \mu \mathrm{l}$ of preimmune serum.

Immunocytochemistry. Adult male Sprague-Dawley rats $(n=5)$ were deeply anesthetized with Chloropent $(4.25 \%$ chloral hydrate, $9 \mathrm{mg} / \mathrm{ml}$ pentobarbital, $86 \mathrm{~mm} \mathrm{MgSO}_{4}, 30 \%$ propylene glycol, $13 \%$ ethanol; i.p. dose $6-10 \mathrm{ml} / \mathrm{kg}$ body weight) and transcardially perfused with $3 \%$ paraformaldehyde followed by $10 \%$ sucrose $(200 \mathrm{ml}$ over $10 \mathrm{~min}$ for each). Brains were removed and cryoprotected in $30 \%$ sucrose at $4^{\circ} \mathrm{C}$. Forty micron sections were cut on a freezing-sliding microtome and collected in $50 \mathrm{~mm}$ 'Iris-buffered saline $\mathrm{pH} 7.2$ (TBS). Sections were preblocked in TBS with $4 \%$ normal goat serum (NGS), $0.4 \%$ Triton $\mathrm{X}-100$, avidin $(10 \mu \mathrm{g} / \mathrm{ml})$, and biotin $(50 \mu \mathrm{g} / \mathrm{ml})$, before incubation with primary antibody (in TBS containing $0.1 \%$ Triton X-100 and $2 \%$ NGS) over 2 nights at $4^{\circ} \mathrm{C}$. DAT/Nt and DAT/e2 antibodies were used at 1 $\mu \mathrm{g} / \mathrm{ml}$, and tyrosine hydroxylase (TH) antibody (Boehringer-Mannheim) was diluted 1:100. The avidin-biotin complex method (ABC; Vector, Burlingame, CA) was used to visualize DAT/Nt and DAT/e2 immunoreactivity, and the peroxidase-immunoperoxidase method (Sternberger-Meyer) was used to visualize TH immunoreactivity. Tissue was rinsed between all steps with TBS $3 \times 10 \mathrm{~min}$. The peroxidase reaction was developed in $0.05 \%$ DAB and $0.01 \% \mathrm{H}_{2} \mathrm{O}_{2}$ until a dark brown reaction product was evident. Sections were rinsed several times in TBS, mounted on subbed slides, dehydrated in alcohols, defatted in xylene, and coverslipped for analysis under a Nikon Microphot-FXA light microscope.

Two separate control experiments were run in parallel to confirm specificity. For preadsorption controls, parallel series of rat brain sections were incubated in DAT/Nt-specific or DAT/e2-specific antibodies that had been preadsorbed for $30 \mathrm{~min}$ at room temperature against either the $\mathrm{Nt}$ - or the e2-fusion proteins $(50-100 \mu \mathrm{g}$ fusion protein) conjugated to Affi-Gel beads (Bio-Rad). For a 6-OHDA lesion control experiment, a male Sprague-Dawley rat $(300 \mathrm{~g})$ was given a lesion of the dopaminergic mesostriatal system via injection of $3 \mu \mathrm{g}$ of 6-hydroxydopamine per two sites $(-3.8 / 1.9 / 9.2 \mathrm{~mm}$ and $-4.3 / 1.5 / 8.7 \mathrm{~mm}$ relative to bregma) following anesthetization with xylazine $(15 \mathrm{mg} / \mathrm{kg})$ and ketamine $(75 \mathrm{mg} / \mathrm{kg})$. Two weeks after injection of neurotoxin, the animal was perfusion-fixed and processed for light microscopic immunocytochemistry as described above. 


\section{$\mathrm{kDa}$}
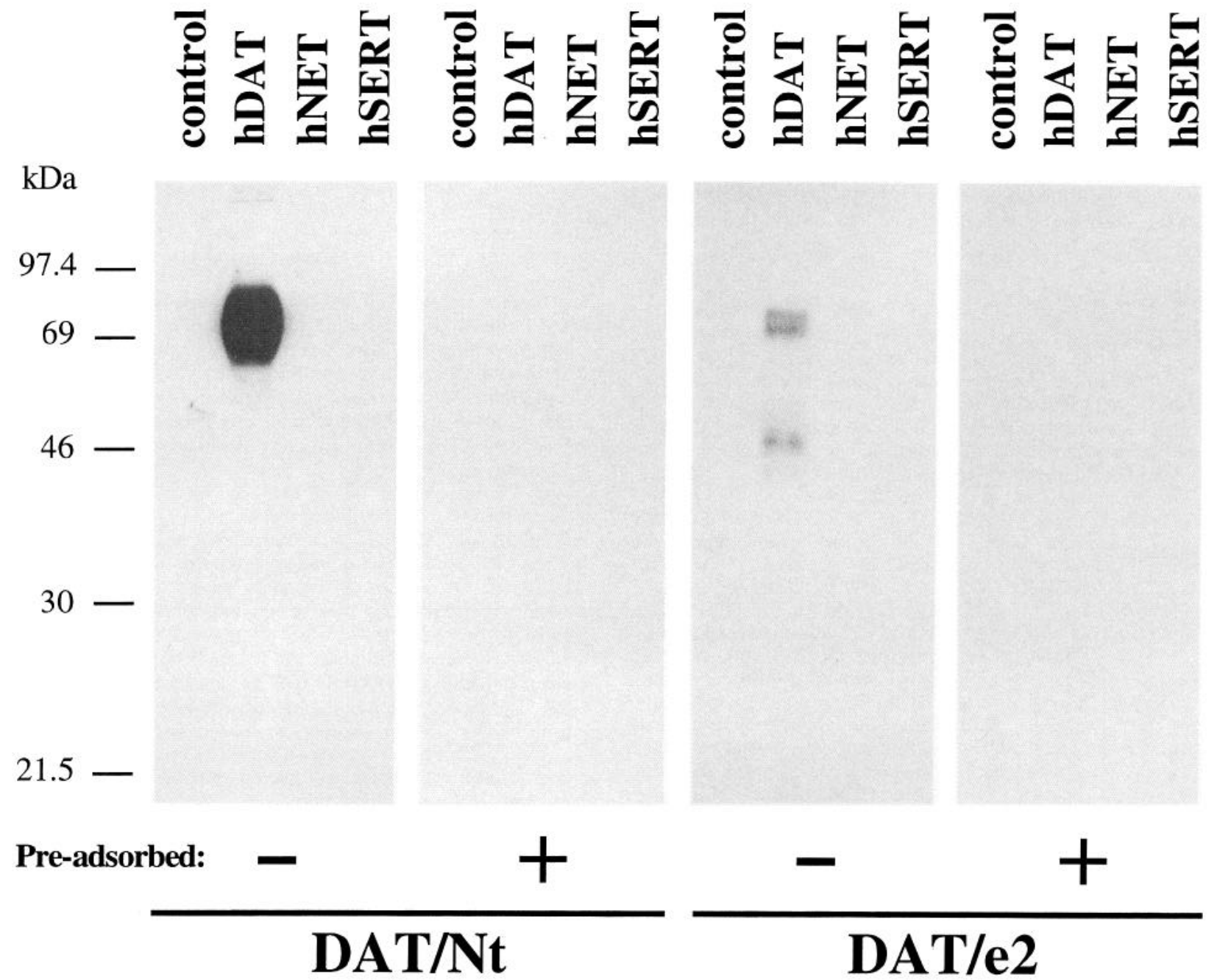

Figure 1. Molecular specificity of DAT antibodies by Western blot analysis. DAT/Nt ( first and second panels) and DAT/e2 (third and fourth panels) antibodies were blotted against membranes from SK-N-MC or HeLa cells transfected with either human dopamine transporter ( $h D A T$; pRc/ CMV in SK-N-MC), human norepinephrine transporter ( $h N E T$; pBluescript in HeLa), or human serotonin transporter ( $h S E R T$; pBluescript in HeLa) cDNAs. Twenty-five micrograms of protein were loaded per lane. Control lane represents SK-N-MC cells transfected with only the nonligated pRc/ CMV plasmid used to express hDAT; control lane for pBluescript plasmid in HeLa cells (not shown) was identical to SK-N-MC control. After being probed with either DAT/Nt ( first panel) or DAT/e2 (third panel) antibody, the blots were reprobed with the same antibody that had been preadsorbed with $100 \mu \mathrm{g}$ of homologous fusion protein (second and fourth panels, respectively). Molecular weight standards are designated on left in kilodaltons.

\section{Results}

Immunoblot analysis

Affinity-purified antibodies directed against either Nt or e2 of human DAT were characterized by Western blotting against membranes from SK-N-MC or HeLa cells transfected with cDNA encoding human dopamine, norepinephrine (hNET), or serotonin transporter (hSERT), and rat and human brain membranes. When blotted against cloned transporters, DAT/Nt antibody specifically detected an intense, broad band between 70 $80,000 \mathrm{kDa}$ in the hDAT lane and did not recognize hNET or hSERT (Fig. 1). Similar results were found with the DAT/e2 antibody (Fig. 1). An additional lower molecular weight band was present of approximately $50-55,000 \mathrm{kDa}$, possibly representing a degradation product. Preadsorption of either antibody with homologous fusion protein abolished all immunoreactive bands (Fig. 1). DAT/Nt antibody also recognized native DAT protein in rat and human membranes (Fig. 2), with apparent molecular weights of approximately the same size as the cloned transporter. In parallel experiments, no immunoreactivity was detected by affinity purified antibodies directed against $\mathrm{Ct}$.

\section{Immunoprecipitation}

The ability of DAT antiserum to immunoprecipitate solubilized native human DAT from caudate membranes is depicted in Figure 3. DAT antisera was able to precipitate up to $95 \%$ of the specific ${ }^{3} \mathrm{H}$-WIN35,428 binding activity to digitonin solubilized DAT in a concentration-dependent manner. Virtually identical results were obtained from transfected Sf9 or Y1 cells expressing the cloned hDAT (data not shown). Preimmune sera showed no effect on ${ }^{3} \mathrm{H}$-WIN 35,428 binding activity in either native membranes or in transfected cells. We also assessed the ability of DAT antiserum to immunoprecipitate native DAT labeled by ${ }^{3} \mathrm{H}-\mathrm{GBR}-12935$. Under conditions in which ${ }^{3} \mathrm{H}-\mathrm{GBR}-12935$ binding activity is restricted to DAT (Niznik et al., 1991), approximately $90 \%$ of the specific binding of this ligand (i.e., mazindol-sensitive binding sites) was immunoprecipitated and 


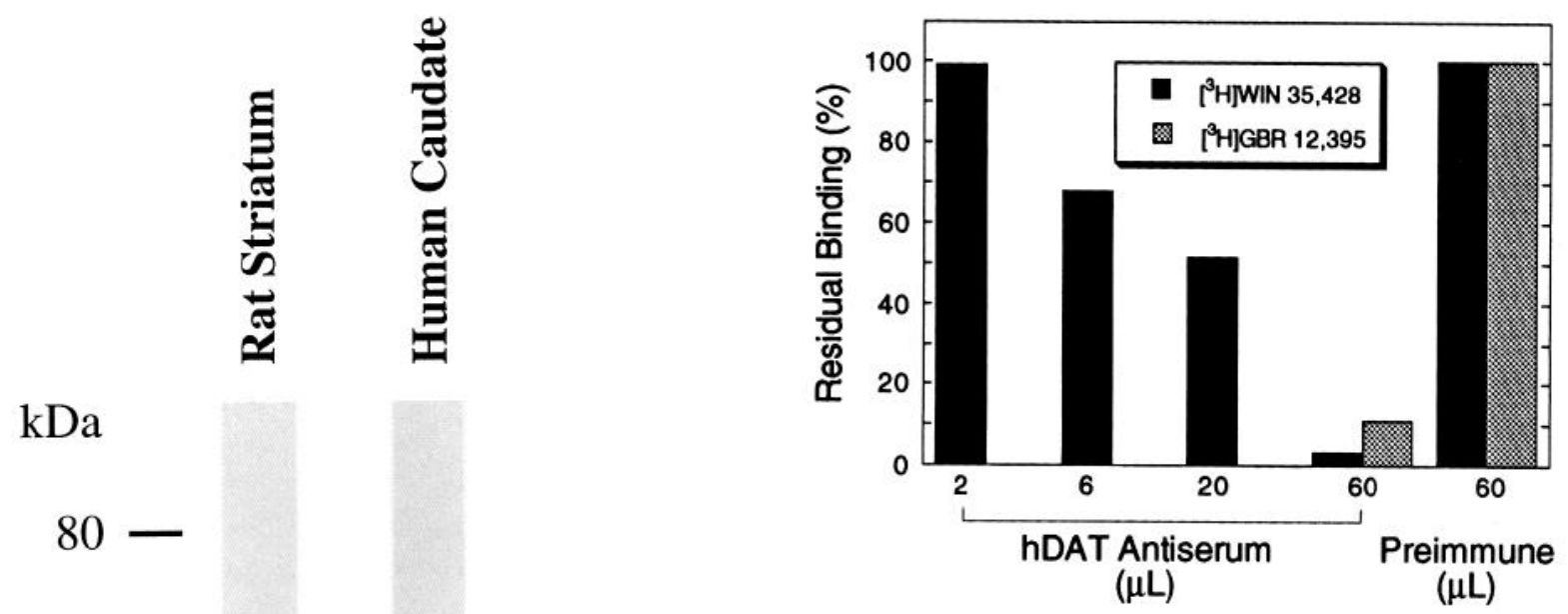

Figure 3. Immunoprecipitation of ${ }^{3} \mathrm{H}-\mathrm{WIN} 35,428$ and ${ }^{3} \mathrm{H}-\mathrm{GBR}-12935$ binding activity with anti-hDAT antiserum. Human caudate membranes were solubilized with $1 \%$ digitonin and incubated with the indicated volume of anti-human DAT antiserum coupled with protein A-Sepharose for approximately $12 \mathrm{hr}$ at $4^{\circ} \mathrm{C}$. Following centrifugation, the supernatants were assayed for both ${ }^{3} \mathrm{H}-\mathrm{WIN} 35,428$ and ${ }^{3} \mathrm{H}-\mathrm{GBR}-12935$ binding activity as described in Materials and Methods. Values represent the means of duplicate determinations of two independent experiments (100\% activity represents approximately $200 \mathrm{fmol} / \mathrm{ml}$ of ${ }^{3} \mathrm{H}-\mathrm{WI}$ $\mathrm{N} 35,428(40 \mathrm{~nm})$ and approximately $500 \mathrm{fmol} / \mathrm{ml}$ of ${ }^{3} \mathrm{H}-\mathrm{GBR}-12935$ (10 nM)binding activity to solubilized membranes).

with homologous fusion protein. Preadsorption with heterologous fusion protein had no effect on any immunolabeling. Finally, unilateral 6-OHDA lesion of the nigrostriatal pathway abolished DAT/Nt immunoreactivity in ipsilateral striatum (Fig. $4 B$ ) and cingulate cortex (Fig. 4C).

\section{Immunocytochemical regional distribution}

In general, DAT/Nt and DAT/e2 demonstrated equivalent re-

\section{DAT/Nt}

Figure 2. Western blot detection of native rat and human DAT. DAT/ $\mathrm{Nt}$ antibody was blotted against membranes from rat striatum $(100 \mu \mathrm{g}$ protein) and human caudate (150 $\mu \mathrm{g}$ protein). Molecular weight standards are designated on left in kilodaltons.

paralleled the immunoprecipitation profile observed for ${ }^{3} \mathrm{H}-$ WIN35,428. Sites labeled by ${ }^{3} \mathrm{H}-\mathrm{GBR}-12935$ that are mazindol insensitive and identified as neuronal P450 proteins (Niznik et al., 1990; Allard et al., 1994) were not immunoprecipitated.

\section{Specificity of DAT/Nt- and DAT/e2-specific immunocytochemistry}

The regional distribution of DAT immunoreactivity at the level of striatum (Fig. $4 A$ ) had a high correlation to the distributions of other dopaminergic markers at this site [e.g., TH, D1, and D2 receptors (Levey et al., 1993; Ciliax et al., 1994)]. Antibody specificity was further determined by preadsorption or 6-OHDA lesion. DAT/Nt and DAT/e2 antibodies were preadsorbed with either the DAT/Nt- or DAT/e2-fusion proteins. For both antibodies, preadsorption with the homologous fusion protein decreased striatal immunoreactivity nearly to background levels (data not shown). In addition, DAT/Nt immunoreactivity in axon fibers of cingulate cortex was abolished by preadsorption only gional distributions of DAT in rat brain tissue sections; however, since DAT/Nt had superior sensitivity, our report will focus on those results. Affinity-purified DAT/Nt-specific antibodies localized transporter protein to dopaminergic cell groups and their terminal fields (Fuxe et al., 1985) (Fig. 5A-H). The primary dopaminergic cell groups that project to basal ganglia from ventral midbrain (A9-A10) were all positive for DAT immunoreactivity. Neurons and processes of substantia nigra pars compacta (SNc; cell group A9) were immunoreactive for DAT (Fig. 5E,F). While these perikarya and dendrites were well labeled, DAT immunoreactivity was less intense than tyrosine hydroxylase immunoreactivity and less intense than DAT immunoreactivity in striatum (see below). Ventral tegmental area (VTA; cell group A10) had a labeling pattern similar to SNc, with moderately stained perikarya and a dense meshwork of immunolabeled processes (Fig. 5G). However, aspects of the medial VTA displayed much less immunoreactivity, whereas TH immunoreactivity was concentrated in this same region. DAT-labeled axons were observed emanating from the dopamine cell groups into the medial forebrain bundle, and could be followed to projection sites in more rostral brain regions (Fig. 5D). Retrorubral field (cell group A8) also had well-labeled perikarya and processes (Fig. $5 \mathrm{H}$ ).

In contrast, no specific immunolabeling was seen in any region of hypothalamus, in which dopamine cell groups A11-A15 are located. Nor was immunolabel observed in periaqueductal dopamine cells of A11a, which project to hypothalamus. Other 

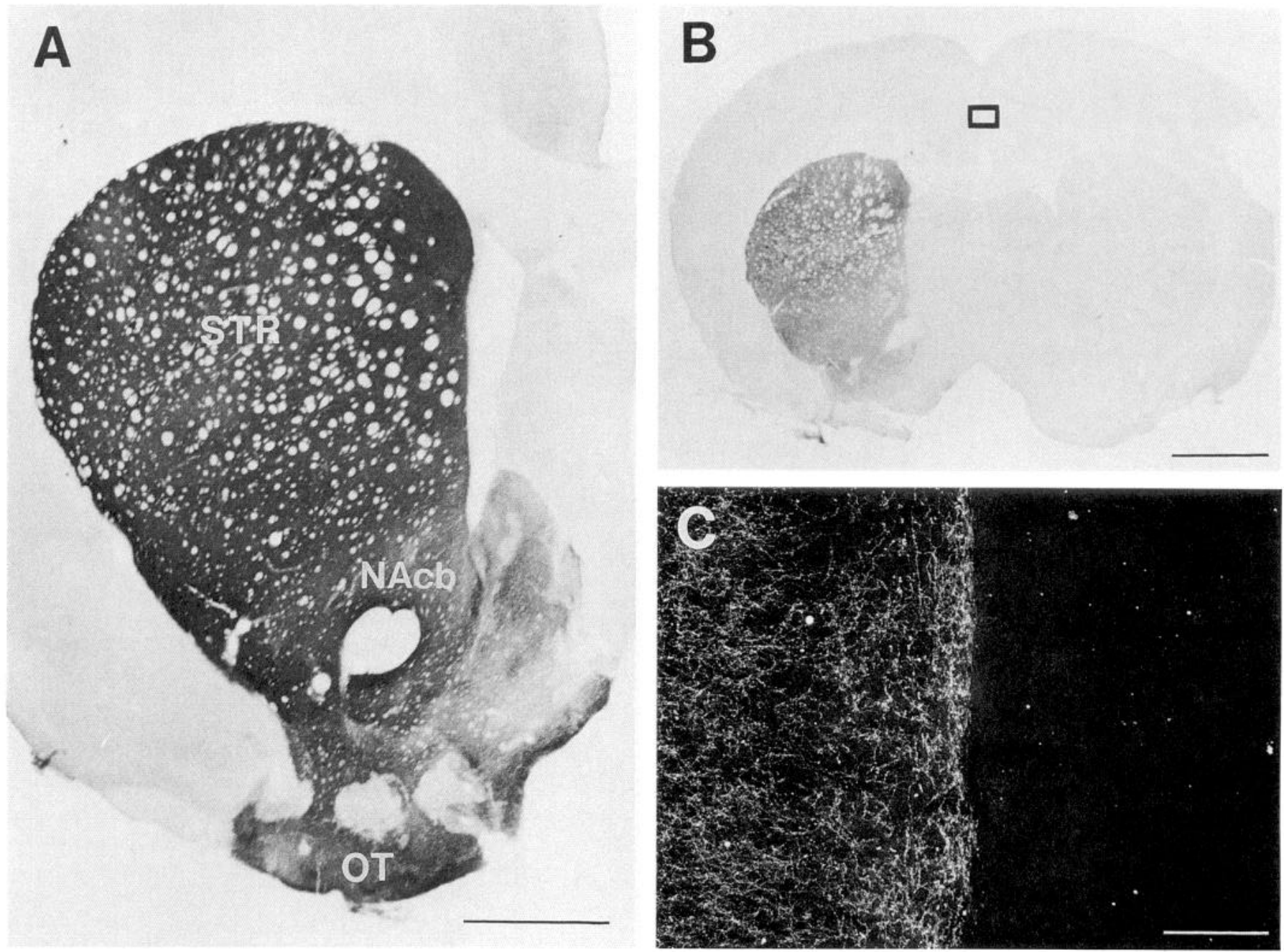

Figure 4. DAT immunocytochemistry in rat striatum and cingulate cortex and its abolishment after 6-OHDA lesion. A, DAT immunocytochemistry in rat striatum $(S T R)$, nucleus accumbens $(N A c b)$, and olfactory tubercle $(O T)$. B, DAT immunocytochemistry in unilateral 6-OHDA lesioned rat striatum. Lesioned side is indicated by the nicked cortex on right; nonlesioned side on left. $C$, Dark-field micrograph of DAT immunocytochemistry in cingulate cortex from the region demarcated by the box in $B$. Scale bars: $A, 1 \mathrm{~mm} ; B, 2 \mathrm{~mm} ; C, 200 \mu \mathrm{m}$.

monoaminergic cell groups located in locus coeruleus and the raphe nuclei had no detectable immunoreactivity.

DAT immunoreactivity was also concentrated in the terminal fields of dopaminergic ventral midbrain neurons. DAT immunoreactivity was concentrated in neuropil of dorsal and ventral striatum (Figs. $4 A, 5 A, B$ ), in axonal fibers and arborizations of the globus pallidus (Fig. $5 C$ ) and entopeduncular nucleus (Fig. $5 D$ ), and in cingulate cortex (Fig. 6A), claustrum/dorsal endopiriform nucleus, and subnuclei of amygdala. Also, fine granular labeling was seen in bed nucleus of the stria terminalis and the intermediate lateral septum.

DAT labeling of neuropil in neostriatum and nucleus accumbens had both diffuse and granular appearances (Fig. 5B). In addition, labeling of neostriatum was heavier in the outer rim and in several patches (Fig. 5A). Labeling of ventral striatum displayed marked inhomogeneities (Fig. 4A), particularly rostrally. These labeling patterns had the characteristics of compartmental organization, that is, striosome-matrix compartments, though this was not confirmed during these experiments.

Axonal fibers in medial forebrain bundle, globus pallidus, entopeduncular nucleus, cingulate cortex, and claustrum/dorsal endopiriform nucleus were densely immunoreactive. In some cases, the axon fibers were long with few branches, while in other cases, the fibers appeared tortuous. Most of these regions had combinations of these forms, e.g., globus pallidus and entopeduncular nucleus had both types, whereas cingulate cortex

Figure 5. DAT immunocytochemistry in terminal fields and perikarya of midbrain dopamine cell groups (A8-A10) of rat. A,Striatum. Note concentrated immunoreactivity in patch-like regions (arrows) and outer rim of striatum (arrowheads). B, High-power micrograph of striatum. Note punctate labeling in neuropil. $C$, Globus pallidus. $D$, Entopeduncular nucleus $(E P N)$ and medial forebrain bundle $(m f b)$. $E$, Substantia nigra $[S N r$, pars reticulata; $S N c$, pars compacta (A9 cell group); $c p$, cerebral peduncle]. $F$. High-power micrograph of scattered perikarya (arrowheads) and processes in substantia nigra pars compacta. Note perinuclear labeling. $G$, Ventral tegmental area (Al0 cell group; $V T A_{m}$, medial ventral tegmental area; $V T A_{1}$, lateral ventral tegmental area; $f r$, fasciculus retroflexus; $m p$, mammillary peduncle; arrow, midline of section). $H$, Retrorubral field (A8 cell group). Scale bars: $A, D$, and $G, 250 \mu \mathrm{m} ; B$ and $F, 25 \mu \mathrm{m} ; C$ and $H, 100 \mu \mathrm{m} ; E, 500 \mu \mathrm{m}$. 

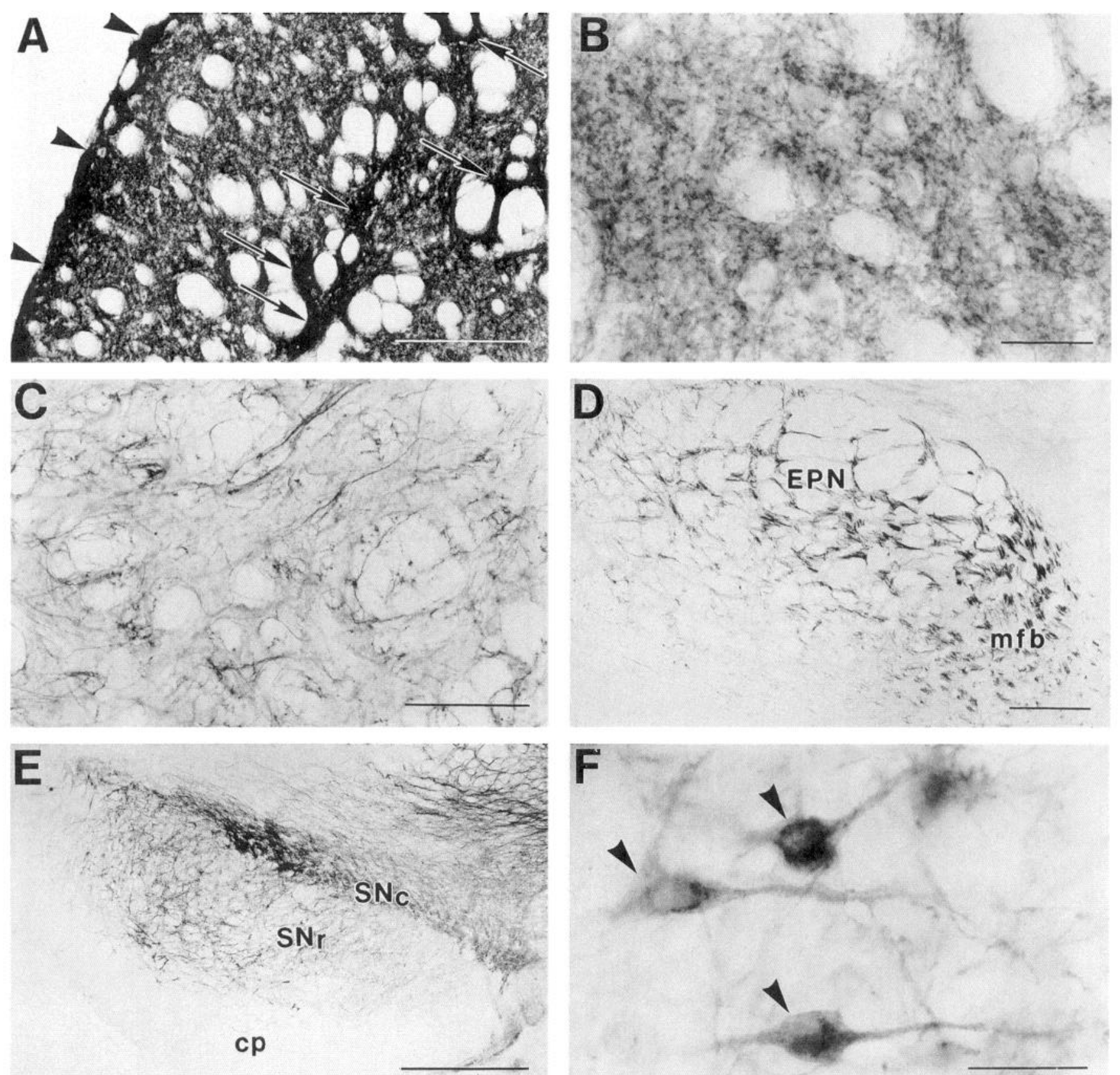

G

H
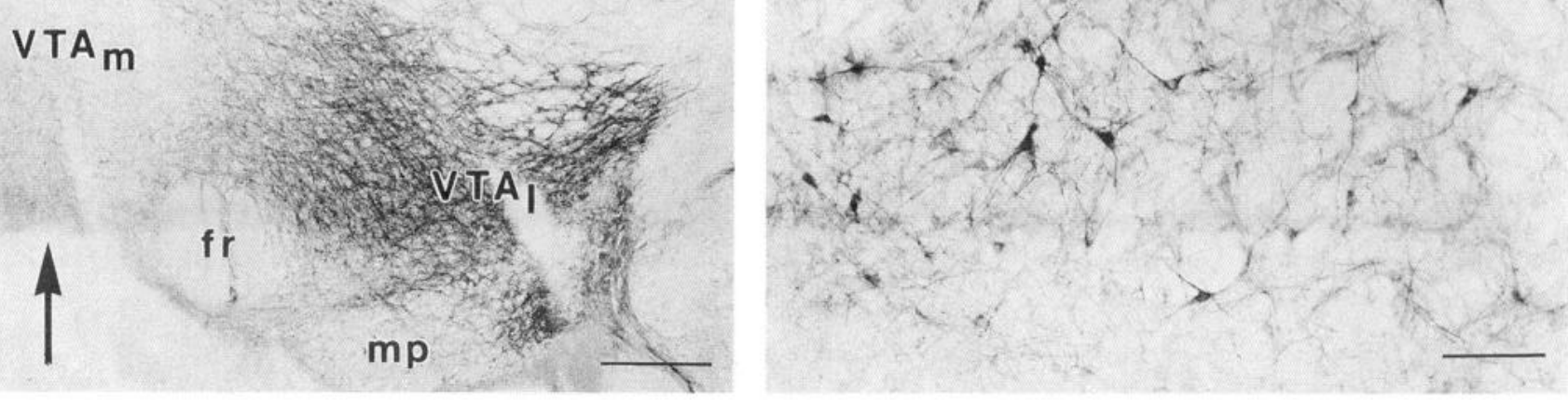

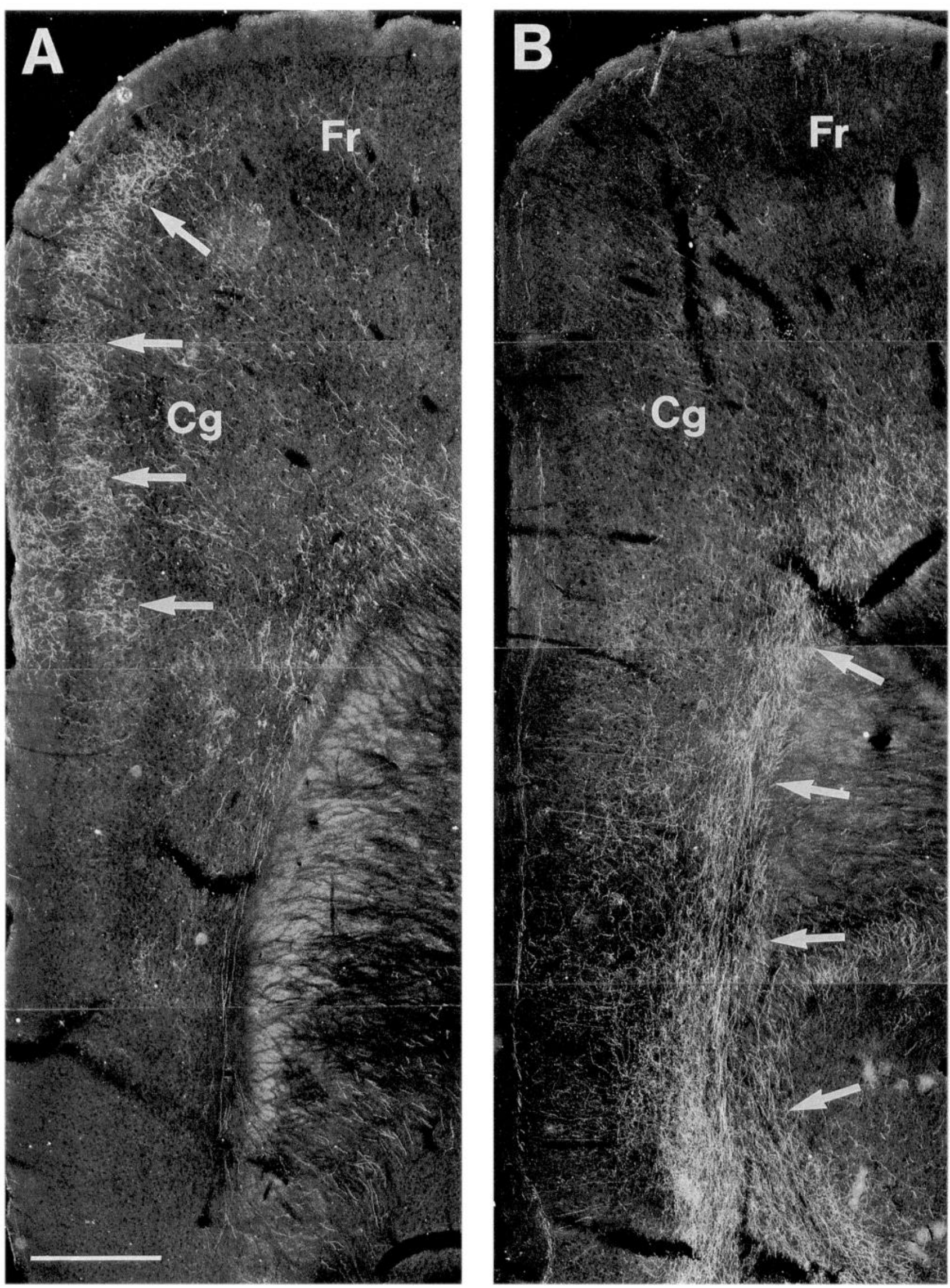

Figure 6. DAT and TH immunocytochemistry in rat cingulate cortex. A, Dark-field micrograph of DAT immunocytochemistry in rat cingulate cortex. Axonal plexus is labeled (arrows) in superficial layers of cingulate $(C g)$ but not in frontal $(F r)$ cortex. $B$, TH immunocytochemistry in a nearly adjacent section. Note that the plexus labeled in $A$ is absent and that a dense axonal pathway is labeled in deep layers of more ventral cortical regions (arrows). Scale bar, $500 \mu \mathrm{m}$. 
and claustrum/dorsal endopiriform nucleus contained many more of the tortuous fibers. However, medial forebrain bundle consisted of bundles of labeled fibers cut in cross-section (in the coronal plane) with a few axons of intermediate length, presumably diverging from the bundles and targeting a nearby nucleus. Although striatum displayed dense neuropil labeling that made morphological characterization difficult, the same types of varicose fibers were occasionally observed. In rostrodorsal cortical regions, DAT-immunoreactive fibers appeared to travel parallel to the outer surface of corpus callosum in layer 6 of cortex. At the cingulum, these fibers diverged from deep layer 6 as they entered cingulate cortex and formed a dense plexus (Fig. 6A). TH immunoreactivity in nearly adjacent sections did not label the same plexus and was generally lighter at this site (Fig. 6B).

In amygdala, DAT immunoreactivity was discretely localized to individual subnuclei. The intercalated nuclei were the most intensely labeled with virtually all specific labeling due to densely intertwined axons. The pattern and intensity were similar to that of striatum. The lateral central amygdaloid nucleus had light to moderate labeling with a fine granular appearance. Immunoreactivity was highest at the core of the nucleus and low around the edge. The basolateral and lateral nuclei had very sparse, immunoreactive axons.

\section{Discussion}

\section{Antibody specificity}

Several independent criteria verified the specificity of DAT/Nt and DAT/e2 antibodies. First, both antibodies specifically recognized expressed hDAT, but not hNET nor hSERT, in transfected cell membranes on immunoblots. Moreover, both antibudies recognized native transporter protein from rat and human membranes. Molecular weights of the immunoreactive bands (70-80 kDa) from blots of cloned or native transporter are similar to those of photoaffinity labeled DAT (Lew et al., 1991). In addition, immunoprecipitation and immunoblotting of rat DAT with antipeptide antibodies have identified a protein of approximately $80 \mathrm{kDa}$ (Vaughan et al., 1993). Thus, DAT antibodies recognize full length species. Second, immunoprecipitation studies demonstrated that DAT antisera recognized DAT binding sites labeled in native membranes (and the cloned DAT in transfected cell membranes) by either ${ }^{3} \mathrm{H}-\mathrm{GBR}-12935$ or ${ }^{3} \mathrm{H}$ WIN 35,428 in a dose-dependent manner, indicating that the binding activity and sensitivity for both of these ligands are conferred by one polypeptide (Patel et al., 1993; Vaughan et al., 1993; Pristupa et al., 1994). Although these experiments used an indirect measure of immunoprecipitation (radiolabeling of residual transporter binding sites), several immunological and pharmacological controls support the specificity of the assay: (1) preimmune sera did not immunoprecipitate any binding sites, (2) DAT antisera immunoprecipitated transporter binding sites that recognized distinct classes of radioligands (dialkylpiperazine and aromatic-substituted tropane), and (3) DAT antisera did not immunoprecipitate the ${ }^{3} \mathrm{H}-\mathrm{GBR}-12935$ binding sites characterized as neuronal $\mathbf{P} 450$ proteins (mazindol insensitive). These controls indicate that immunoprecipitation with DAT antisera was specific for the transporter protein. Immunoprecipitation protocols that isolate radiolabeled species would, however, provide more direct evidence of specific recognition of transporter protein by DAT antisera and await future characterization studies. Third, preadsorption of DAT/Nt and DAT/e2 antibodies with homologous fusion proteins (but not with heterologous) substantially reduced immunoreactivity in both immunoblotting and immunocytochemistry experiments. Fourth, 6-hydroxydopamine lesion of the medial forebrain bundle abolished DAT/Nt immunoreactivity in ipsilateral striatum and cingulate cortex. Fifth, DAT/Nt and DAT/e2 antibodies target distinct epitopes, yet displayed the same general regional distributions, suggesting a single antigen. Sixth, distribution of DAT immunoreactivity in terminal fields and perikarya of ventral midbrain dopamine neurons is in good agreement with the respective distributions of DAT mRNA in perikarya (Giros et al., 1991; Shimada et al., 1992) and of DAT binding sites (Donnan et al., 1991; Richfield, 1991; Mennicken et al., 1992), dopamine innervation (Fuxe et al., 1985), and dopamine uptake activity in both brain regions. Therefore, these immunochemical assays firmly establish the specificity of these anti-fusion protein antibodies for DAT.

\section{Immunocytochemical regional distribution}

DAT distribution in rat brain was concentrated in regions of dopamine cell groups and dopaminergic innervation, as determined by TH immunocytochemistry (Fuxe et al., 1985), dopamine immunocytochemistry (Voorn and Buijs, 1987; Kalsbeek et al., 1988; Voorn et al., 1988) or dopamine histofluorescence (Fuxe et al., 1985). For example, neostriatum, nucleus accumbens, and olfactory tubercle were all densely labeled for DAT and are also richly innervated with mesencephalic dopaminc axon terminals. Regions with less concentrated labeling (e.g., globus pallidus, entopeduncular nucleus, and medial forebrain bundle) also have less dopaminergic innervation. In addition, the light microscopic patterns of DAT and TH immunolabeling are identical for these respective regions. Furthermore, the regional distribution of DAT immunoreactivity also parallels the autoradiographic regional distribution of DAT binding sites (Donnan et al., 1991; Richfield, 1991; Mennicken et al., 1992). Finally, the cells of origin for the majority of mesostriatal/mesolimbic axons, grouped in SNc and VTA, express DAT mRNA (Giros et al., 1991; Shimada et al., 1992). Thus, the DAT protein is synthesized in these perikarya then transported down the axons to the forebrain targets. This conclusion is also supported by our 6-OHDA lesion experiment.

DAT immunoreactivity in substantia nigra was concentrated in perikarya, dendrites, and axons of pars compacta. Many D $\mathrm{DT}$ labeled dendrites descended from pars compacta into pars reticulata (similar to the distribution of D2 receptor immunoreactivity (Levey et al., 1993; Ciliax et al., 1994)). This observation provides anatomical support for a dopamine uptake mechanism on pars compacta dendrites in this region. Some studies suggest that dopamine is released and is taken back up by the same neural elements (Silbergeld and Walters, 1979); however, this view has been contested (Kelly et al., 1985; Simon and Ghetti, 1993). Immunolaheling in perikarya and dendrites was lighter than that in the target regions, which coincides with the lower levels of DAT binding reported for this region in quantitative autoradiography studies (Donnan et al., 1991; Richfield, 1991; Mennicken et al., 1992). Thus, DAT protein may be selectively enriched in axons and axon terminals.

In contrast, little or no DAT immunoreactivity was detected in the hypothalamus, which is consistent with the fact that hypothalamic dopamine system is independent from the midbrain dopamine systems (Fuxe et al., 1985) and has low DAT mRNA (Cerruti et al., 1993) and binding sites (Mennicken et al., 1992). The lack of DAT protein in hypothalamus may account for its selective protection from 6-OHDA lesions (Yokoyama et al., 1993). The absence of DAT immunoreactivity in cell group 
A1 la contrasts with expression of DAT mRN $\Lambda$ in this cell group (Cerruti et al., 1993). Either the protein is not translated efficiently or it is rapidly degraded resulting in expression levels below the sensitivity of the methods.

\section{Comparison of TH and DAT as immunocytochemical dopaminergic markers}

Since $\mathrm{TH}$ is also expressed in other catecholamine neurons, it is not a specific marker for dopamine neurons. However, as expected, DAT-labeled neurons and processes were generally included within the distribution of $\mathrm{TH}$ immunoreactivity. For instance, dorsal and ventral striatum had high levels of both markers with a similar pattern of labeling, both in terms of the granular texture and apparent compartmental organization. Axonal fiber labeling of DAT in globus pallidus, entopeduncular nucleus, and medial forebrain bundle was equivalent to TH labeling in these same regions. However, there were several examples of mismatch between TH and DAT immunoreactivity. First, the hypothalamic dopaminergic system had intense TH immunoreactivity in dopamine cell groups but no DAT immunoreactivity in the same regions. Second, medial VTA was enriched with $\mathrm{TH}$ immunoreactivity but DAT immunoreactivity was absent. In contrast, the lateral VTA was enriched in both markers. Third, in a projection site of the mesocorticolimbic neurons, TH immunoreactivity in cingulate cortex did not delineate the same dense axonal plexus in superficial layers as did DAT immunoreactivity. Instead, TH immunoreactivity labeled axon fibers concentrated in the deep layers, many of which may represent noradrenergic afferents (Morrison et al., 1979). TH immunoreactivity in superficial layers was much lighter and the labeled axons sparser than that found with DAT immunoreactivity. Thus, DAT and TH antibodies appear to label different subpopulations of dopaminergic axons and terminals in superficial layers. (Further studies employing double labeling methods will be needed to delineate this relationship.) These putative subpopulations could belong to different dopaminergic neurons or to the same neurons but comprise different segments or branches of the axon fibers. Either explanation would imply a complex organization of dopamine synthesis, release, and reuptake in the cingulate cortex. Interestingly, dopamine released in medial prefrontal cortex can diffuse six times farther than in striatum or nucleus accumbens, as determined by reuptake (S. E. Eldon, K. C. Horst, T. D. Ely, and C. D. Kilts, unpublished observations) and in vivo voltammetry studies (Garris and Wightman, 1994), which argues for a nonsynaptic (paracrine or volumetric) model of dopaminergic neurotransmission in this region. Fourth, distinct distributions of TH and DAT may similarly occur in neostriatum. Preliminary electron microscopic immunocytochemical data from our laboratory indicate that DAT immunoreactive striatal terminals form both symmetric and asymmetric synapses (B. J. Ciliax, S. M. Hersch., and A. I. Levey, unpublished observations), in contrast to $\mathrm{TH}$, which predominantly labcls the former set of terminals (Pickel et al., 1981; Arluison et al., 1984; Freund et al., 1984). Thus, there is evidence that dopaminergic markers TH and DAT have overlapping distributions but each marker can identify subtypes of dopaminergic pathways or processes. The implications of this dichotomy will be important for understanding the function and regulation of discrete dopaminergic systems.

\section{Inhomogeneities}

Both DAT/Nt and DAT/e2 were enriched in patches in rat dorsal striatum, analogous to those reported for D1- and D2-receptor immunocytochemistry (Levey et al., 1993; Ciliax et al., 1994), and were of similar size and shape to rat striosomes visualized by $\mu$-opiate receptor autoradiography in adult or TH immunocytochemistry in newborn (Gerfen et al., 1987). Ventral striatum also demonstrated distinct inhomogeneities. These data indicate that the distribution of DAT protein in rat striatum is compartmentally organized. Autoradiographic data has shown that DAT binding sites in striatum are compartmentally organized in several species (Graybiel et al., 1987; Graybiel et al., 1993). Patches enriched with DAT may relate to functionally distinct compartments in striatum identified by in vivo voltammetry (May and Wightman, 1989) and dopamine histofluorescence (Olson et al. 1972), which have demonstrated microheterogeneities in dopamine turnover, release, and uptake.

In conclusion, antifusion protein DAT antibodies were specific for the transporter in several immunochemical assays. Affinitypurified DAT/Nt and DAT/e2 antibodics immunolocalized DAT in rat brain to regions concentrated with dopamine terminal fields or the cells of origin. As a marker for dopaminergic neurons, DAT immunocytochemistry had a high degree of correlation with distinct TH-positive dopaminergic systems, yet several mismatches were also observed, particularly in medial VTA, hypothalamic dopamine cell groups, and cingulate cortex. Preliminary electron microscopic immunocytochemistry data using these antibodies indicates that subtypes of dopamine terminals may be present in striatum. Detailed comparison of the distribution of DAT with other dopaminergic markers will be essential for understanding how distinct dopaminergic pathways mediate mesostriatal and mesocorticolimbic function. Finally, these antibodies will be useful for the study of transporter regulation (via both Western blot analysis and immunocytochemistry) under certain neurological and psychiatric disorders that involve dopaminergic systems, e.g., Parkinson's Disease, Tourette's Syndrome, schizophrenia and drug addiction.

\section{References}

Allard P, Marcusson JO, Ross SB (1994) [3H]GBR-12935 binding to cytochrome P450 in the human brain. J Neurochem 62:342-348.

Arluison M, Dietl M, Thibault J (1984) Ultrastructural morphology of dopaminergic nerve terminals and synapses in the striatum of the rat using tyrosine hydroxylase immunocytochemistry: a topographical study. Brain Res Bull 13:269-285.

Boja JW, Vaughan R, Patel A, Shaya EK, Kuhar MJ (1994) The dopamine transporter. In: Dopamine receptors and transporters: pharmacology, structure, and function (Niznik HB, ed), pp 611-644. New York: Dekker.

Cerruti C, Walther DM, Kuhar MJ, Uhl GR (1993) Dopamine transporter mRNA expression is intense in rat midbrain neurons and modest outside midbrain. Brain Res Mol Brain Res 18:181-186.

Chinaglia G, Alvarez FJ, Probst A, Palacios JM (1992) Mesostriatal and mesolimhic dopamine uptake binding sites are reduced in Parkinson's disease and progressive supranuclear palsy: a quantitative autoradiographic study using $\left[{ }^{3} \mathrm{H}\right]$ mazindol. Neuroscience 49:317327.

Ciliax BJ, Hersch SM, Levey AI (1994) Immunocytochemical localization of D1 and D2 receptors in rat brain. In: Dopamine receptors and transporters: pharmacology, structure, and function (Niznik HB, ed), pp 383-399. New York: Dekker.

Ciliax BJ, Heilman C, Edmunds S, Hersch SM, Levey AI (1995) Antifusion protein antibodies specific for receptor subtypes. In: Methods in neurosciences, Vol 25, Receptor molecular biology (Sealfon SC, ed). Orlando: Academic.

Donnan GA, Kaczmarczyk SJ, McKenzie JS, Kalnins RM, Chilco PJ, Mendelsohn FA (1989) Catecholamine uptake sites in mouse brain: distribution determined hy quantitative $\left[{ }^{3} \mathrm{H}\right]$ mazindol autoradiography. Brain Res 504:64-71.

Donnan GA, Kaczmarczyk SJ, Paxinos G, Chilco PJ, Kalnins RM, 
Woodhouse DG, Mendelsohn FA (1991) Distribution of catecholamine uptake sites in human brain as determined by quantitative $\left[{ }^{3} \mathrm{H}\right]$ mazindol autoradiography. J Comp Neurol 304:419-434.

Freund TF, Powell JF, Smith AD (1984) Tyrosine hydroxylase-immunoreactive boutons in synaptic contact with identified striatonigral neurons, with particular reference to dendritic spines. Neuroscience 13:1189-1215.

Fuxe K, Agnati LF, Kalia M, Goldstein M, Andersson K, Härfstrand A (1985) Dopaminergic systems in the brain and pituitary. In: The dopaminergic system (Flückiger E, Müller EE, Thorner MO, eds), pp 11-25. New York: Springer Sandoz.

Garris PA, Wightman RM (1994) Different kinetics govern dopaminergic transmission in the amygdala, prefrontal cortex, and striatum: an in vivo voltammetric study. J Neurosci 14:442-450.

Gerfen CR, Baimbridge KG, Thibault J (1987) The neostriatal mosaic: III. Biochemical and developmental dissociation of patch-matrix mesostriatal systems. J Neurosci 7:3935-3944.

Giros B, Caron MG (1993) Molecular characterization of the dopamine transporter. Trends Pharmacol Sci 14:43-49.

Giros B, el MS, Bertrand L, Caron MG (1991) Cloning and functional characterization of a cocaine-sensitive dopamine transporter. FEBS Lett 295:149-154.

Giros B, el MS, Godinot N, Zheng K, Han H, Yang FT, Caron MG (1992) Cloning, pharmacological characterization, and chromosome assignment of the human dopamine transporter. Mol Pharmacol 42: 383-390.

Graybiel AM, Moratalla R (1989) Dopamine uptake sites in the striatum are distributed differentially in striosome and matrix compartments. Proc Natl Acad Sci USA 86:9020-9024.

Graybiel AM, Hirsch EC, Agid YA (1987) Differences in tyrosine hydroxylase-like immunoreactivity characterize the mesostriatal in nervation of striosomes and extrastriosomal matrix at maturity. Proc Natl Acad Sci USA 84:303-307.

Graybiel AM, Moratalla R, Quinn B, DeLanney LE, Irwin I, Langston JW (1993) Early-stage loss of dopamine uptake-site binding in MPTP-treated monkeys. Adv Neurol 60:34-39.

Kalsbeek A, Vourn P, Buijs RM, Pool CW, Uylings HB (1988) Development of the dopaminergic innervation in the prefrontal cortex of the rat. J Comp Neurol 269:58-72.

Kelly E, Jenner P, Marsden CD (1985) Evidence that $\left[{ }^{3} \mathrm{H}\right]$ dopamine is taken up and released from nondopaminergic nerve terminals in the rat substantia nigra in vitro. $\mathrm{J}$ Neurochem $45: 137-144$.

Kopin IJ, Markey SP (1988) MPTP toxicity: implications for research in Parkinson's disease. Annu Rev Neurosci 11:81-96.

Levey AI, Hersch SM, Rye DB, Sunahara RK, Niznik HB, Kitt CA Price DL, Maggio R, Brann MR, Ciliax BJ (1993) Localization of D1 and D2 dopamine receptors in brain with subtype-specific antibodies. Proc Natl Acad Sci USA 90:8861-8865.

Lew R, Grigoriadis D, Wilson A, Boja JW, Simantov R, Kuhar MJ (1991) Dopamine transporter: deglycosylation with exo- and endoglycosidases. Brain Res 539:239-246.

May LJ, Wightman RM (1989) Heterogeneity of stimulated dopamine overflow within rat striatum as observed with in vivo voltammetry. Brain Res 487:311-320.

Mennicken F, Savasta M, Peretti RR, Feuerstein C (1992) Autoradiographic localization of dopamine uptake sites in the rat brain with ${ }^{3}$ H-GBR 12935. J Neural Transm 87:1-14.

Morrison JH, Molliver ME, Grzanna R, Coyle JT (1979) Noradrenergic innervation patterns in three regions of medial cortex: an immunofluorescence characterization. Brain Res Bull 4:849-857.

Niznik HB, Tyndale RF, Sallee FR, Gonzalez FJ, Hardwick JP, Inaba $T$, Kalow W (1990) The dopamine transporter and cylochrome P45OIID1 (debrisoquine 4-hydroxylase) in brain: resolution and iden- tification of two distinct $\left[{ }^{3} \mathrm{H}\right] \mathrm{GBR}-12935$ binding proteins. Arch Biochem Biophys 276:424-432.

Niznik HB, Fogel EF, Fassos FF, Seeman P (1991) The dopamine transporter is absent in parkinsonian putamen and reduced in the caudate nucleus. J Neurochem 56:192-198.

Olson L, Seiger A, Fuxe K (1972) Heterogeneity of striatal and limbic dopamine innervation: highly fluorescent islands in developing and adult rats. Brain Res 44:283-288.

Patel A, Uhl G, Kuhar MJ (1993) Species differences in dopamine transporters: postmortem changes and glycosylation differences. J Neurochem 61:496-500.

Pickel VM, Beckley SC, Joh TH, Reis DJ (1981) Ultrastructural immunocytochemical localization of tyrosine hydroxylase in the neostriatum. Brain Res 225:373-385.

Pifl C, Giros B, Caron MG (1993) Dopamine transporter expression confers cytotoxicity to low doses of the parkinsonism-inducing neurotoxin 1-methyl-4-phenylpyridinium. J Neurosci 13:4246-4253.

Pristupa ZB, Wilson JM, Hoffman BJ, Kish SJ, Niznik HB (1994) Pharmacological heterogeneity of the cloned and native human dopamine transporter: disassociation of $\left[{ }^{3} \mathrm{H}\right]$ WIN 35,428 and $\left[{ }^{3} \mathrm{H}\right] \mathrm{GBR}$ 12,935 binding. Mol Pharmacol 45:125-135.

Richfield EK (1991) Quantitative autoradiography of the dopamine uptake complex in rat brain using [ $\left.{ }^{3} \mathbf{H}\right] \mathrm{GBR}$ 12935: binding characteristics. Brain Res 540:1-13.

Shimada S, Kitayama S, Walther D, Uhl G (1992) Dopamine transporter mRNA: dense expression in ventral midbrain neurons. Brain Res Mol Brain Res 13:359-362.

Silbergeld EK, Walters JR (1979) Synaptosomal uptake and release of dopamine in substantia nigra: effects of gamma-aminobutyric acid and substance P. Neurosci Lett 12:119-126.

Simon JR, Ghetti B (1993) Is there a significant somatodendritic uptake of dopamine in the substantia nigra? Evidence from the weaver mutant mouse. Neurochem Int 22:471-477.

Singer HS, Hahn IH, Moran TH (1991) Abnormal dopamine uptake sites in post-mortem striatum from patients with Tourette's syndrome. Ann Neurol 30:558-562.

Smith DB, Johnson KS (1988) Single-step purification of polypeptides expressed in Escherichia coli as fusions with glutathione S-transferase. Gene 67:31-40.

Tyndale RF, Sunahara R, Inaba T, Kalow W, Gonzalez FJ, Niznik HB (1991) Neuronal cytochrome P450IID1 (debrisoquine/sparteinetype): potent inhibition of activity by $(-)$-cocaine and nucleotide sequence identity to human hepatic P450 gene CYP2D6. Mol Pharmacol 40:63-68.

Vandenbergh DJ, Persico AM, Uhl GR (1992) A human dopamine transporter cDNA predicts reduced glycosylation, displays a novel repetitive element and provides racially-dimorphic TaqI RFLPs. Brain Res Mol Brain Res 15:161-166.

Vaughan RA, Uhl G, Kuhar MJ (1993) Recognition of dopamine transporters by antipeptide antibodies. Mol Cell Neurosci 4:209-215

Voorn P, Buijs RM (1987) Ultrastructural demonstration of dopamine in the central nervous system. In: Monoaminergic neurons: light microscopy and ultrastructure (Steinbusch HWM, ed), pp 241-264. New York: Wiley.

Voorn P, Kalsbeek A, Jorritsma BB, Groenewegen HJ (1988) The preand postnatal development of the dopaminergic cell groups in the ventral mesencephalon and the dopaminergic innervation of the striatum of the rat. Neuroscience 25:857-887.

Yokoyama C, Okamura H, Ibata Y (1993) Resistance of hypothalamic dopaminergic ncurons to neonatal 6-hydroxydopamine toxicity. Brain Res Bull 30:551-559.

Zigmond MJ, Abercrombie ED, Berger TW, Grace AA, Stricker EM (1990) Compensations after lesions of central dopaminergic neurons: some clinical and basic implications. Trends Neurosci 13:290-296. 